\title{
World diabetes day 2017 focus: antepartum hyperglycaemia (or gestational prediabetes) is more in women below 40 years
}

Sir,

Prediabetes is a state of hyperglycaemia that is above normal, but below blood glucose threshold for diabetes mellitus. As part of the theme for World Diabetes Day of 2017, it has been articulated by the International Diabetes Federation, that up to $16 \%$ of births may be affected by this condition and it is estimated that $50 \%$ of the affected antenatal patients are under 30 years old. ${ }^{1}$ The notion of gestational prediabetes, hyperglycaemia in pregnancy as a clinical condition is yet to be seriously discussed in regards to prediabetes in pregnancy. ${ }^{2}$ Instead, it seems to be subsumed in the discourse of gestational diabetes mellitus. This subsuming position is evident in the fact that even in discussion of management challenges of the 'hyperglycaemia in pregnancy' condition, blood glucose thresholds for gestational diabetes refers to higher versus lower cut-offs, but never refers to prediabetes. ${ }^{3}$

The consequence is that antenatal patients who present with prediabetes at gestational diabetes screening are never given the medical attention. For instance, there is acknowledgement of lack of agreement regarding blood glucose threshold, but also a recommendation that "a diagnosis of GDM needs to be made" to target treatment. ${ }^{3}$ Given albeit subconscious disregard for gestational prediabetes, dearth of data may be presumed. However, the focus of World Diabetes Day of 2017 indicates evidence of what is known. ${ }^{1}$ Perhaps, what is yet unknown includes how prevalence of gestational diabetes compares with gestational prediabetes, especially in stratified age groups.

In our evaluation of prevalence of gestational diabetes in stratified age subgroups at Central hospital Warri, Nigeria, attempt was made to select results that could have been referred for confirmation of prediabetes if patients were to be non-antenatal. A total of 3589 blood glucose results were reviewed for prevalence of diabetes versus prediabetes; and the mean age were compared. First, it was found that, in this particular dataset, prevalence of diabetes and prediabetes were equal $(n=$ $210 ; 5.85 \%)$. Simple student t-test comparison of age showed that diabetes population are (39.7 years) older than the prediabetes group (34.0years) with strong statistical significance $(\mathrm{p}<0.000001)$. When data were sorted by age and stratified, it is observed that.

- $20 \%$ of diabetes population are younger than 30 years, relative to $24 \%$ of prediabetes.
- $75 \%$ of diabetes population are older than 40 years, relative to $4 \%$ of prediabetes.

- Prevalence of prediabetes is higher in all stratified age strata below 40 years and lower afterwards. The reverse is the case for diabetes (Figure 1).

- Among the 210 prediabetic results, FBS identified $81 \%$ relative to $19 \%$ from RBS.

- Among the 210 diabetic results, FBS identified 93\% relative to $7 \%$ from RBS.

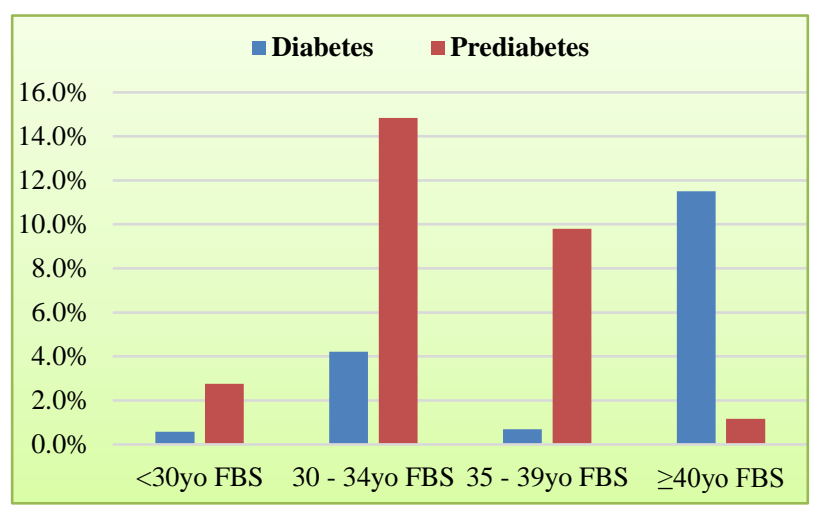

Figure 1: Potential prevalence of prediabetes relative to diabetes in stratified age groups.

The notion of gestational prediabetes has been suggested since about 7 years ago. ${ }^{2}$ It has been identified that pregnant women with prediabetic levels of blood glucose have significantly high risks of adverse maternal and neonatal outcomes. ${ }^{4}$ Yet, much discourse has been focused on women with GDM. ${ }^{5-8}$ This is despite the reported finding of a high FBS level during pregnancy as "the risk factor most commonly associated with future risk of type 2 diabetes". ${ }^{5}$ Indeed, there are few studies on women with prediabetes following GDM, but the notion of prediabetes in pregnancy being potential predisposition to postpartum diabetes has yet to be given necessary attention. ${ }^{7,9}$ That is, while gestation diabetes leading to postpartum prediabetes and onward type 2 diabetes is relatively established; it needs to be appreciated that antepartum prediabetes is predictor of postpartum type 2 diabetes. ${ }^{5,10}$ In other words, it is high time to appreciate antepartum hyperglycaemia as gestational prediabetes.

Upon such appreciation i.e. of the notion and risk of hyperglycaemia in pregnancy or antepartum/gestational prediabetes, the observation reported here can be put into perspective in practice that these are women at risk, but arguably being overlooked. It is important to note the 
result reported here that antepartum hyperglycaemia visà-vis gestational prediabetes is more in women who, by virtue of age, would ordinarily not be investigated for diabetes. This draws attention to the World Diabetes Day of 2017 focus that pregnant women require improved access and care. ${ }^{1}$

\section{Orru M. I. ${ }^{1}$, Nwose E. U. ${ }^{1,2 *}$, Bwititi P. T. ${ }^{3}$,} Igumbor E. O. ${ }^{1}$

${ }^{1}$ Department of Public and Community Health, Novena University Ogume, Nigeria

${ }^{2}$ Department of Community Health, Charles Sturt University, New South Wales, Australia ${ }^{3}$ Department of Biomedical Sciences, Charles Sturt University, New South Wales, Australia

*Correspondence: Nwose E. U.,

E-mail: enwose@csu.edu.au

\section{REFERENCES}

1. International Diabetes Federation. World Diabetes Day 2017: 2017 [2 $2^{\text {nd }}$ Nov, 2017]. Available at https://www.idf.org/our-activities/world-diabetesday/wdd-2017.html.

2. Ray JG, Berger H, Lipscombe LL, Sermer M. Gestational prediabetes: a new term for early prevention? Indian J Med Res. 2010;132:251-5.

3. Farrar D. Hyperglycemia in pregnancy: prevalence, impact, and management challenges. Int J Women's Health. 2016;8:519-27.

4. Sukumaran S, Madhuvrata P, Bustani R, Song S, Farrell TA. Screening, diagnosis and management of gestational diabetes mellitus: A national survey. Obstetric Medicine. 2014;7(3):111-5.

5. Kim C, Newton KM, Knopp RH Gestational diabetes and the incidence of type 2 diabetes: a systematic review. Diabetes Care. 2002;25:1862-8.
6. Bhavadharini B, Anjana RM, Mahalakshmi MM, Maheswari K, Kayal A, Unnikrishnan R, et al. Glucose tolerance status of Asian Indian women with gestational diabetes at 6 weeks to 1 year postpartum (WINGS-7). Diabetes Res Clin Pract. 2016;117:227.

7. O'Dea A, Tierney M, McGuire BE, Newell J, Glynn LG, Gibson I, et al. Can the onset of type 2 diabetes be delayed by a group-based lifestyle intervention in women with prediabetes following gestational diabetes mellitus (GDM)? Findings from a randomized control mixed methods trial. J Diabetes Res. 2015;2015:798460.

8. Zhang S, Liu H, Zhang C, Wang L, Li N, Leng J, et al. Maternal glucose during pregnancy and after delivery in women with gestational diabetes mellitus on overweight status of their children. BioMed Res Int. 2015;2015:543038.

9. Perez-Ferre N, Del Valle L, Torrejon MJ, Barca I, Calvo MI, Matia P, et al. Diabetes mellitus and abnormal glucose tolerance development after gestational diabetes: A three-year, prospective, randomized, clinical-based, Mediterranean lifestyle interventional study with parallel groups. Clin Nutr. 2015;34(4):579-85.

10. Buchanan TA, Xiang AH, Kjos SL, Trigo E, Lee WP, Peters RK. Antepartum predictors of the development of type 2 diabetes in Latino women 1126 months after pregnancies complicated by gestational diabetes. Diabetes. 1999;48(12):2430-6.

Cite this article as: Orru MI, Nwose EU, Bwititi PT, Igumbor EO. World diabetes day 2017 focus: antepartum hyperglycaemia (or gestational prediabetes) is more in women below 40 years. Int $\mathrm{J}$ Reprod Contracept Obstet Gynecol 2018;7:355-6. 